\title{
Using Space Syntax and Information Visualization for Spatial Behavior Analysis and Simulation
}

\author{
Sheng-Ming Wang ${ }^{1}$ \\ Department of Interaction Design \\ National Taipei University of Technology \\ Taipei, Taiwan
}

\author{
Chieh-Ju Huang ${ }^{2}$ \\ Doctoral Program in Design \\ National Taipei University of Technology \\ Taipei, Taiwan
}

\begin{abstract}
This study used space syntax to discuss user movement dynamics and crowded hot spots in a commercial area. Moreover, it developed personas according to its onsite observations, visualized user movement data, and performed a deep-learning simulation using the generative adversarial network (GAN) to simulate user movement in an urban commercial area as well as the influences such move might engender. From a pedestrian perspective, this study examined the crowd behavior in a commercial area, conducted an onsite observation of people's spatial behaviors, and simulated user movement through data-science-driven approaches. Through the analysis process, we determined the spatial differences among various roads and districts in the commercial area, and according to the user movement simulation, we identified key factors that influence pedestrian spatial behaviors and pedestrian accessibility. Moreover, we used the deformed wheel theory to investigate the spatial structure of the commercial area and the synergetic relationship between the space and pedestrians; deformed wheel theory presents the user flow differences in various places and the complexity of road distribution, thereby enabling relevant parties to develop design plans that integrate space and service provision in commercial areas. This research contributes to the interdisciplinary study of spatial behavior analysis and simulation with machine learning applications.
\end{abstract}

Keywords-Spatial behavior; space syntax; information visualization; generative adversarial network (GAN); user movement

\section{INTRODUCTION}

The spatial movement of people has been presented in various forms in different fields. Approaches to demonstrating and discussing movement results are determined by the relationships perceived by researchers between people and spaces. In addition to the quantitative analysis of spatial data, this study discussed from a pedestrian perspective the relationship between crowds and spaces in commercial areas as well as observed the spatial behaviors of pedestrians onsite. Underpinned by a data-science-driven approach, this study simulated pedestrian movement in different scenarios. Through a simulation, this study determined the spatial differences of user movements in local and global environments in a commercial area, identified the key factors affecting pedestrian spatial behaviors, and discerned pedestrian accessibility within the space. Using a deformed wheel theory, we investigated spatial structures and their synergistic relationship with pedestrians. Moreover, we examined the differences of user movements in various areas and the complexity of space and route distribution to provide recommendations on transport and spatial planning as well as to outline a design method for future integration between spaces and services in commercial areas. This study is to discuss the predictions of user spatial behavior and pedestrian movement simulations within the established business area. For the movement of hanging around and the consumption movement except walking are not discussed in this study.

In the following of this paper, we extracted the diverse elements of a city by space syntax, observed and collected pedestrians' movement and behaviors from different groups in a commercial area, segmented personas, and then used a deepleaning GAN to integrate and analyze collected data and perform simulations. Then we discussed how data-sciencedriven concepts and data visualization could be used in the establishment of user movement and environmental behaviors in urban commercial areas. In the end of this paper, we tried to make the recommendations for further study.

\section{LITERATURE REVIEW}

\section{A. Space Syntax and Deformed Wheel Theory}

Urban space planning, which is focused on the relationship between spaces and people, may be analyzed using space syntax. Space syntax involves factors such as the main entrances and exits of cities, means of transport for crossregional travel, and the structure of public spaces. Factors in the discussion of urban space planning include land use, urban functions, and the spatial behaviors of people in an area [1]. Hillier and Han [2] introduced the space syntax theory in "The Social Logic of Space"; it suggests that the movement scale of user activities and spatial distribution can be divided into the following basic elements: axial, convex, and isovist spaces. Space syntax emphasizes the patterns of pedestrian activities in a city, as well as relevant spatial measurements and relationships between spaces and social lives [3]. Space syntax presents graphic spatial data that are then used to discuss environmental factors influencing user' spatial behaviors and experience. Such quantified data reveal the relationships among urban roads, blocks, and buildings [4]. Accordingly, space syntax provides attribute information that can be used in designs for solving or alleviating problems that exist in urban spaces [5].

Taiwanese studies using space syntax are predominantly related to urban planning and geographic environments; space syntax can be used to provide comprehensive and quantitative 
analyses and recommendations for urban and route planning improvement in business activities. Therefore, this study used space syntax as a tool to analyze spatial behaviors and user movement, and then give service design suggestions in the future business environment.

The operation of an urban system can be interpreted using syntactic relation systems, such as symmetry-asymmetry, integration-segregation, the determination of control values, integration of features and control cores, and intelligibility and predictability [6] [7] [8] [9]. The fundamental concept of space syntax is that urban areas can all be represented using matrices of connected spaces; such matrices can be simulated and calculated using a computer and reveal space attributes using data [10]. The nature of space. syntax is to show the interaction among and presentation of spatial patterns, user behaviors, and cultures [11]. Relationships between the spatial patterns of human settlements and activities are presented using business models, social structures, and ideologies [12]. Space syntax can predict the most crowded destinations, which should have the most highly integrated roads placed adjacent to them [13].

Space syntax is a digital tool that facilitates data quantification and provides spatial measurements of personal space and overall layout. It measures the connectivity between spaces as well as a space's connectivity to the overall environment, and furthermore, it calculates the depth and spatial integration of a space. Depth is defined as the minimum steps required to reach a space from another, and connectivity refers to the number of spaces that a space is immediately connected to [14].

In quantitative studies, space syntax presents the spatial layout through topological distance and provides dynamic locations and distribution of people. More crucially, it reveals the walkability as well as pedestrians' movement and route choices [15]. In space assessment, space syntax has three indicators of distance [16] [17] [18]:

- Topological distance: the route with the fewest number of turns.

- Geometric distance: the route with the smallest angle change.

- Metric distance: the route with the shortest length.

According to the theory of topological structures, space syntax contains three basic spatial elements for discussing the relationships among buildings, physical urban spaces, and their functions for activities ([19] Fig. 1):

- Convex space: a space where any two of its points are intervisible points.

- Axial space: a space formed by straight lines, such as roads.

- Isovist space: the total space that can be viewed from any point, in which the relationships between each connecting spatial element can also be viewed.

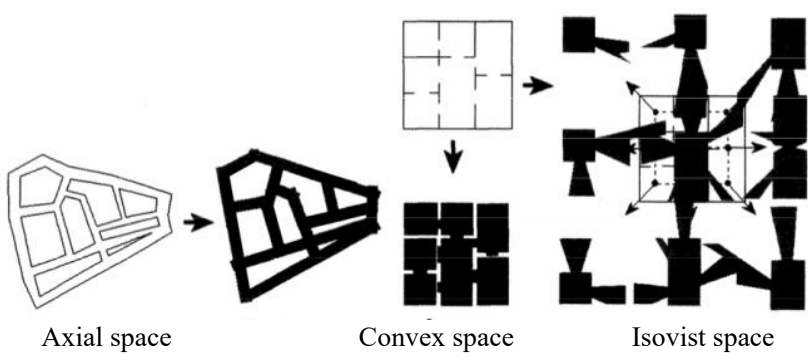

Fig 1. Models of Space Syntax's Three Spatial Elements [20a].

Space syntax transforms physical spaces into topological structures that comprise nodes and lines. Fig. 2 depicts the process of using quantitative indicators to assess the structural characteristics of global or local spaces. These quantitative data are generated using the location of each spatial element and the connections between them in a system. Connected axial lines intersect at a node, which reveals the relationships among structural elements in a spatial system and enables investigation of the relative depth from one structural element to another.

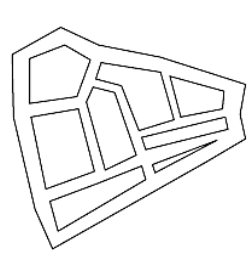

(a)

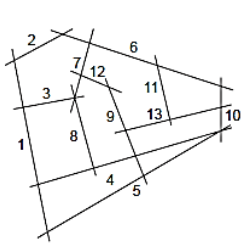

(b)

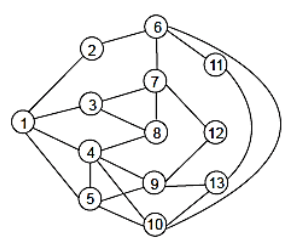

(c)
(a)Road map $\quad$ (b)Axial map $\quad$ (c)Topological map

Fig 2. Spatial Transformation of Space Syntax [20b].

TABLE I. USER SEGMENTS EQUATIONS IN SPACE SyNTAX [21]

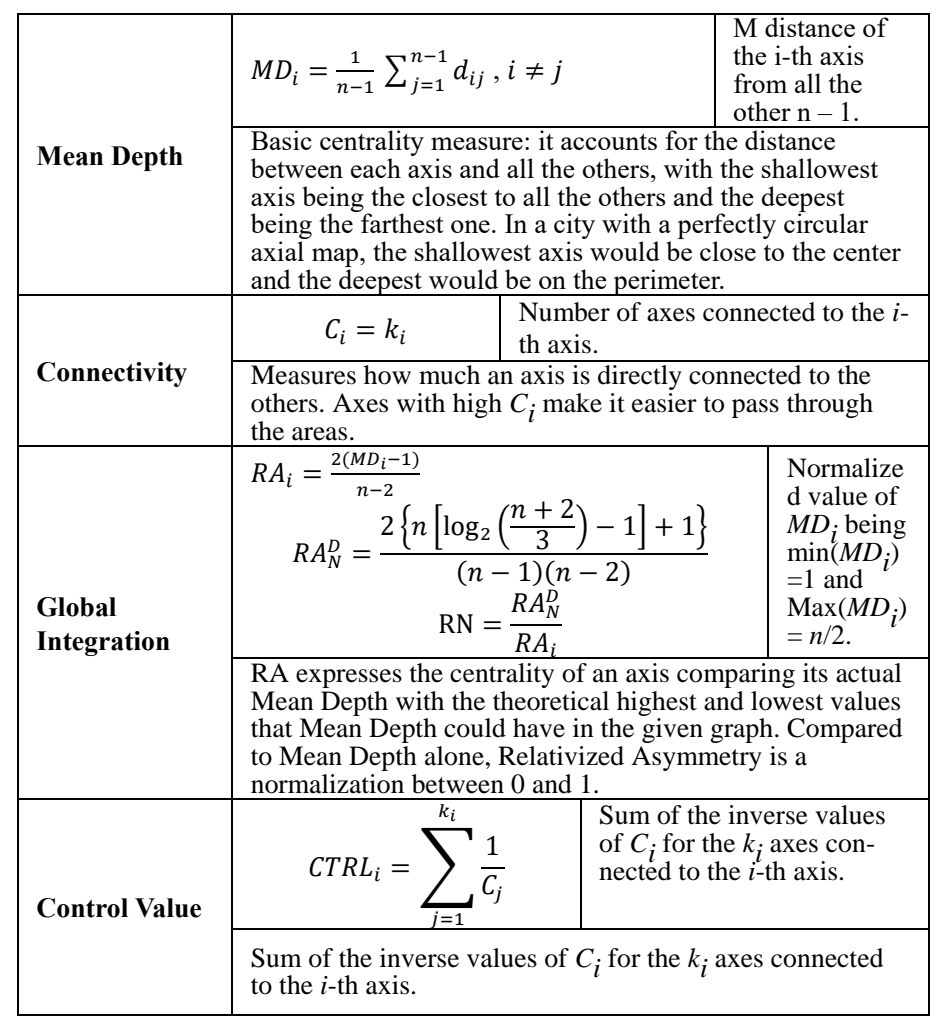


Table I summarizes the Space Syntax measures analyzed in this research.

- Mean Depth (MD): This is a global indicator that measures the mean shortest route of each spatial element to other elements in a system through the relative depth between axial lines.

- Number of connections (Cn): This is a local indicator showing the number of elements adjacent to a particular element; a high $\mathrm{CN}$ value (a high number of immediately connected elements) indicates high accessibility and high publicness of that element.

- Global Integration (Rn): This is a global indicator; a higher RN value of an element indicates higher global integration of that element, namely it being more integrated in a spatial system. Specifically, this means that pedestrians can reach other roads in fewer steps from such an element.

- Control Value (CV): This is a local indicator revealing the extent to which adjacent elements control each other. A high number of elements adjacent to a particular result in high CVs of that element.

Deformed wheel theory in space syntax reveals the original structures of spaces that show the synergic relationships among the spaces. Deformed wheel is a semigrid or hub of lines near the central line that reveals a space's relevant information and characteristics. The spokes of a deformed wheel connect the center to the edge and form an enclosed space. The formation of a space comprises the following six steps:

- Place interaction: From the perspective of nodes and lines, a higher number and longer duration of user activities in a node indicate a lower number and shorter duration of people staying in the lines. By contrast, a higher number and longer duration of people staying in the lines indicate fewer and shorter durations of user activities in the node.

- Place identity: Place identity is related to people in a place. People coexist with places, and place identity emphasizes user in a place.

- Place release: This refers to unexpected and accidental events that elicit user enthusiasm and interests.

- Place realization: This refers to distinct events in a place that underlie its historical or cultural meanings.

- Place creation: This reveals the real needs of a place, such as its commercial or environmental characteristics.

- Place intensification: This denotes a place's features, which are formed through its design, policies, and city structure.

\section{B. Simulation and Visualization of User Movement}

Pedestrian movement is predominantly presented using spatial configuration variables, which represent the characteristics of a road network. By overlaying pedestrian walking distribution on simulated traffic, conflicts between user and traffic can be identified and predicted on certain routes [22]. Accordingly, a quantitative analysis of space syntax provides insight into users' spatial behaviors as well as reveals connectivity among spaces through topological structures derived from axial maps, which also enables discerning the structures of movement networks. Thus, space syntax can be used to investigate how the structure of a spatial network affects people's movement in an urban environment or an indoor space.

To simulate and visualize user movement in commercial areas, this study employed a deep-learning generative adversarial network (GAN) to simulate a large amount of data using user movement data collected during our onsite observations. The study compared visualizations of the simulated data with space syntax results, discussed the similarities and differences between the two methods, and predicted future environmental behaviors of users.

Deep learning is a type of machine learning in artificial intelligence. Machine learning involves training large amounts of data through algorithms to establish mathematical models that facilitate data prediction. Using artificial neural networks (ANNs), which simulate the mechanism of human neural networks, deep learning increases the computational efficiency of central processing units and graphic processing units in computers and has developed rapidly with the increased prevalence of parallel computing. Data analysis of artificial intelligence is underpinned by data collection and algorithms that simulate user analysis patterns. Specifically, artificial intelligence entails a deep-learning mechanism fulfilled by computing.

The mechanism of a GAN comprises two deep-learning ANNs, namely a generator and a discriminator. The mutual learning between the two networks enables the GAN to simulate data that are comparable to the actual data [23]. Fig. 3 presents the mechanisms of a GAN. First, the generator generates random data and the discriminator uses the actual data to determine whether the generated data are flawed; subsequently, the generator corrects its network model accordingly. Through mutual learning and optimization of the model, the generator will be able to generate data that are highly comparable to the actual data. Therefore, when large amounts of simulated data are required under circumstances where few actual data are available, this algorithm may be employed.

This study employed a GAN because such a network can, using the existing actual data, simulate an unlimited amount of data that are similar to the actual data. Therefore, when large amounts of data are required yet only limited sample data are available, a GAN might be used to simulate logical data, as opposed to randomly simulated data. Thus, a GAN is useful for simulation analyses and prediction. 


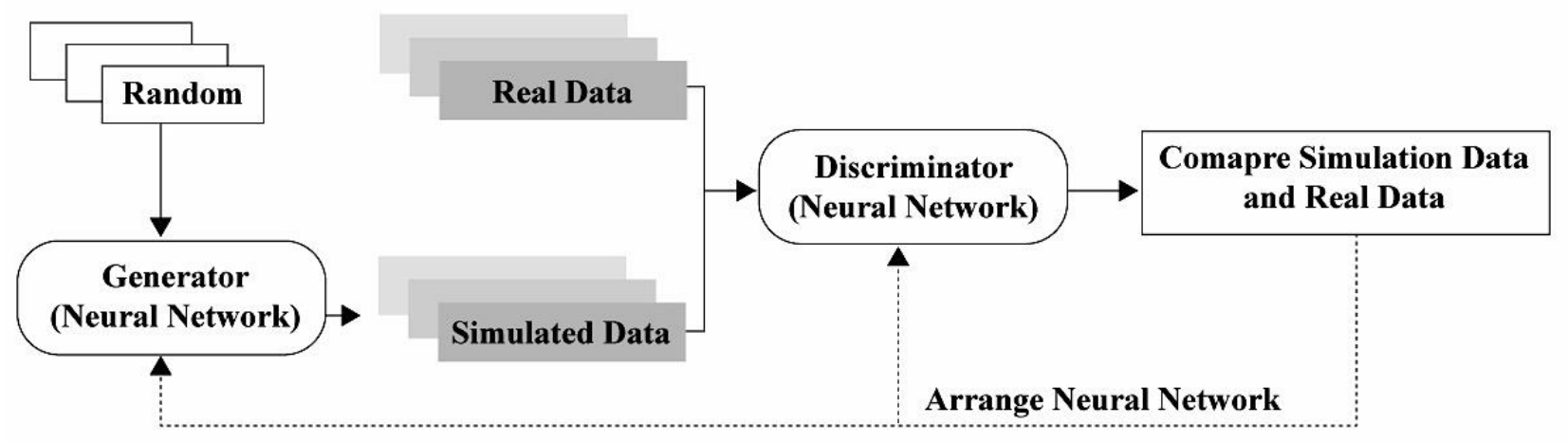

Fig 3. Mechanism of a GAN.

\section{Research Site}

This study focused on the Fengjia night market commercial area (the basic cartographic data are shown in Fig. 4), which is adjacent to Fengjia University and near downtown Taichung; thus, it has become a major tourist destination in Taichung. This commercial area plays a crucial role in the development of Taichung city and is often considered a highlight of a trip to central Taiwan. Fengjia night market, a combination of local culture and geography, has established connections with adjacent areas over more than 40 years of evolution; such an interaction between business and the university has created a unique marketing ecosystem in the region.

From the perspective of city-image design, the basic elements of a city image are edges, paths, nodes, districts, and landmarks [24]. Moreover, urban user activities start and grow outward from these elements. Therefore, this study defined the spatial structure and elements of the Fengjia commercial area from a city-image perspective. We conducted onsite observations to outline the commercial area's spatial structure. According to the observation results (Fig. 4), the section of Wenhua Road located at the upper-left corner (near MOS Burger) is divided into two parts by Fengjia University. We observed that the customer flow split when customers reach the dividing point, and incorporated this observation into our analysis and discussion. In Fig. 4, the major districts of commercial activities are distinguished from other regions; the borders represent the edges of Fengjia commercial area, namely the study's research site; and each line represents a path in this district. Visitors usually entered the commercial area through an entrance near McDonald's (Fengjia Road) or one near the food district on Wenhua Road, which is permits only pedestrian entry at night, whereas students of Fengjia University usually entered the night market through the university's main entranceway (Fengjia Road). The central road of the commercial area is constituted by a section of Fengjia Road between McDonald's and the university's main entranceway, and the intersections between the routes are the nodes where activities occur. The landmarks (represented by triangles) in this commercial area were the two ends of the Fengjia Road section, namely McDonald's and the university's main entranceway, and another university entranceway near MOS Burger. The three landmarks served as the starting points in our analyses.

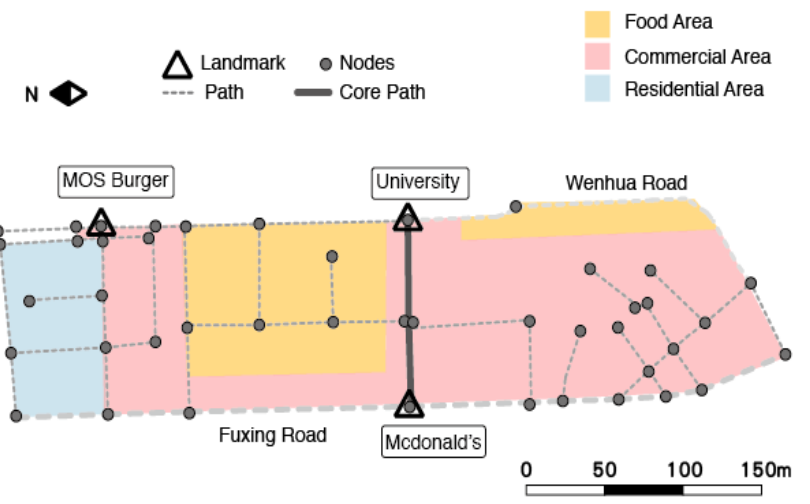

Fig 4. Map of the Fengjia Commercial Area.

This study compiled the locations of nodes and road sections and finalized 67 paths in the commercial area; the commercial area was separated into food, commercial, and residential districts, which were represented by different colors. The landmarks were determined as McDonald's, Fengjia University, and MOS Burger. To provide a clear demonstration of this area, the map is oriented horizontally with a north reference provided.

\section{ReSEARCh Methodology}

\section{A. Research Framework}

According to our literature review, people are the foundational elements in the formation of cities; therefore, research that improves the understanding of and simulates user-behavior patterns and interactive experiences in urban spaces can contribute to the development and improvement of cities and commercial areas as well as improve related information services. Therefore, this study focused on these topics and proposed the research framework in Fig. 5. This study proposed an approach to extract the diverse elements of a city, observed and collected the movement and behaviors of user from different groups in a space, segmented personas, and used a deep-leaning GAN to integrate and analyze collected data and perform simulations. Moreover, this study discussed how data-science-driven concepts and data visualization could be used in the establishment of user movement and environmental behaviors in urban commercial areas. 


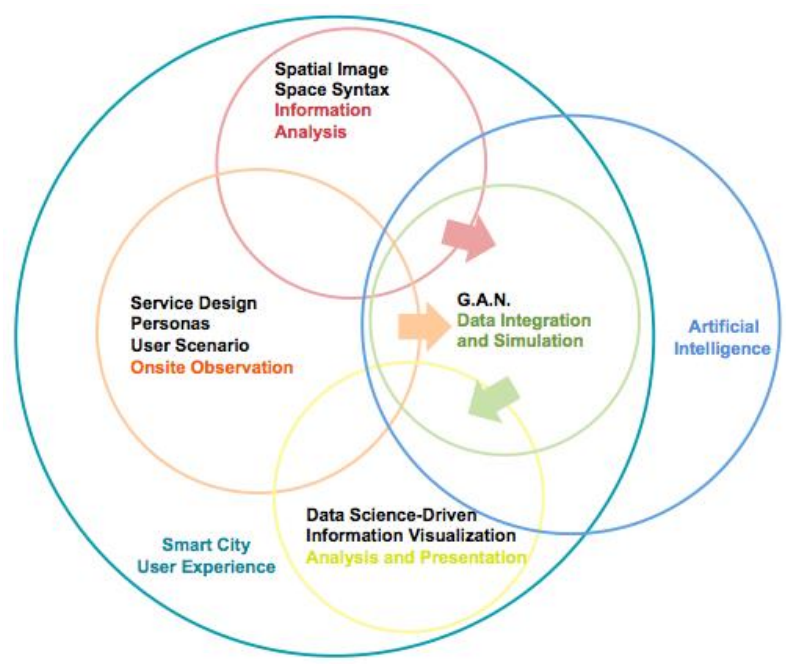

Fig 5. Research Framework.

\section{B. Research Methodology and Assessment}

This study focused on how user movement and a deformed wheel interacted differently in the visualized presentations of data yielded using space syntax and data simulation methods. Therefore, this study first observed user movement and behaviors in the research site, set research objectives, and obtained an overview of the research site using space syntax. Subsequently, this study used relevant software to analyze the axial lines and predict user movement in the research site. We defined personas according to our onsite observations and used these personas in space syntax for axial and isovist analyses of the research site, the results of which were used to predict hot spots where people predominantly gathered. From the deformed wheel perspective, the persona analysis results were used to discuss the dynamics of crowd behavior in different districts, which enabled us to identify crucial elements of service design as well as assessments. Finally, movement data of people with defined personas were inputted into simulation software to produce a large amount of user movement data. Subsequently, this study visualized these data and compared the visualization results with those generated using the deformed wheel theory; finally, it provided recommendations for service design and assessment methods that could be adopted in future research.

Mohammadi et al. [24] proposed the following GAN algorithm:

1) The discriminator (D) and generator (G) perform minimization and maximization algorithms simultaneously:

$\min _{G} \max _{D} V(D, G)=\mathbb{E} x \sim p \operatorname{data}(x)[\log D(x)]+$

2) The weight of the discriminator is updated using the following equation:

$\Delta_{\theta D} \frac{1}{m} \sum_{i=1}^{m}\left[\log D\left(x_{i}\right)+\log \left(1-D\left(G\left(z_{i}\right)\right)\right)\right]$

3) The weight of the generator is updated using the following equation:
$\Delta_{\theta D} \frac{1}{m} \sum_{i=1}^{m}\left[\log \left(1-D\left(G\left(z_{i}\right)\right)\right)\right]$

4) GAN algorithm:

Input: (Source, Destination), Training dataset

For $\mathrm{k}=1$ to I do

Draw $m$ noise samples from $\mathrm{pg}(\mathrm{z})$

Draw $m$ real examples from $\mathrm{pd}(\mathrm{z})$

Update the discriminator $\mathrm{D}$ based on (2)

Draw m noise samples from $\mathrm{pg}(\mathrm{z})$

Update the discriminator $\mathrm{D}$ based on (3)

End for

This study visualized the large amount of data simulated from our experiment and analyses to identify differences between the simulated data and onsite observation results. Such data visualization facilitates interactions for user and reveals relevant information such as visitor backgrounds, purpose of visit, route taken, duration of stay, crowded areas, and distribution of business infrastructure. Moreover, we incorporated scenario simulation into the data visualization and used personas to simulate the spatial experiences for user with various needs and develop a decision support system.

\section{RESEARCH RESULTS AND DISCUSSION}

\section{A. Basic Analysis of Space Syntax}

We labeled all the roads presented in Fig. 4 (see Fig. 6) and used a topological map to analyze the relationships among them (Fig. 7). According to the topological map, the Fengjia commercial area is divided into two main subareas by sections 1 and 2 of Fengiia Road. At deeper spatial layers are the food, commercial, and residential districts to the north, whereas a food-commercial hybrid district to the south is at a shallower layer because it has fewer roads and connections. Table II compiles locations of the commercial area's city-image elements, such as districts, landmarks, edges, and paths.

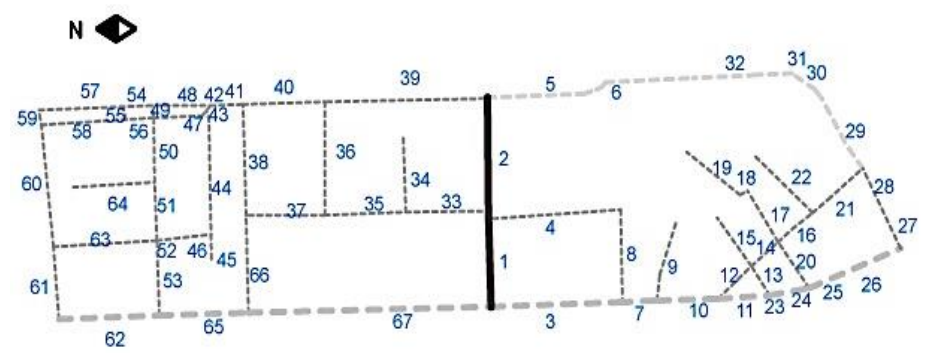

Fig 6. Road Labels in the Fengjia Commercial Area.

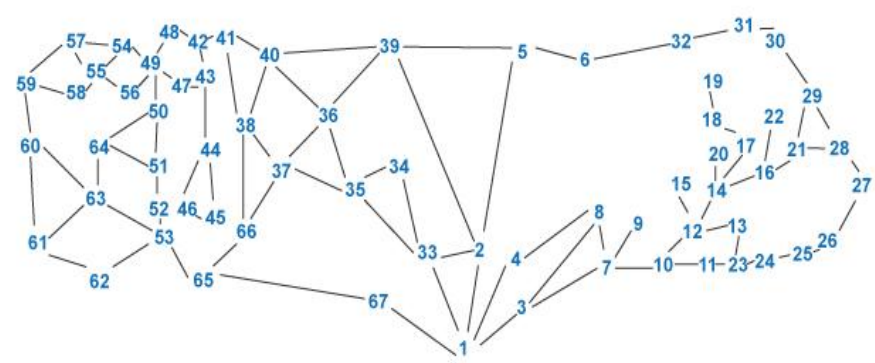

Fig 7. Topological Map of Roads in the Fengjia Commercial Area. 
TABLE II. Distribution OF City-IMAge ElEMENTS IN THE FenGJIA COMMERCIAL AREA

\begin{tabular}{|c|c|c|c|}
\hline & District & Landmark & Edge \\
\hline $\begin{array}{l}\text { Food Area A } \\
\text { (Nearby MOS } \\
\text { Burger) }\end{array}$ & $\begin{array}{l}33,34,35,36, \\
37,38,39,40 \\
66\end{array}$ & & 39,40 \\
\hline $\begin{array}{l}\text { Food Area B } \\
\text { (Food Street) }\end{array}$ & $5,6,32,31,30$ & & $\begin{array}{l}5,6,32 \\
31,30\end{array}$ \\
\hline $\begin{array}{l}\text { Commercial } \\
\text { Area }\end{array}$ & $\begin{array}{l}1 \sim 29,38, \\
41 \sim 53,65 \sim 67\end{array}$ & $\begin{array}{l}\text { Mcdonald's: } 1,3,67 \\
\text { Fang Chia University } \\
: 2,5,39 \\
\text { MOS Burger: } 48,49 \text {, } \\
54\end{array}$ & $\begin{array}{l}39,5,3,7, \\
10,11, \\
23 \sim 29,41, \\
42,48,65, \\
67\end{array}$ \\
\hline Living Area & $49 \sim 62$ & & $\begin{array}{l}54,57, \\
59 \sim 62,\end{array}$ \\
\hline
\end{tabular}

TABLE III. SPace Syntax MEASUREMENTS

\begin{tabular}{|l|l|l|l|l|}
\hline Items & Paths & Max. Value & Min. Value & Average \\
\hline MD & 67 & 9.694 & 4.439 & 6.152 \\
\hline $\mathrm{Rn}$ & 67 & 1.044 & 0.467 & 0.723 \\
\hline $\mathrm{Cn}$ & 67 & 5 & 2 & 3.582 \\
\hline
\end{tabular}

According to Table II, the top three landmarks are all located within the commercial district, which may be because the commercial district constitutes the largest area, and thus has the most roads passing through it. Food districts are distributed in two places; the one near MOS Burger has more roads passing through it than does the one on Wenhua Road.

Using space syntax theory, we incorporated relevant cartographic data into DepthmapX for calculation and analyses, which revealed layers of roads in the Fengjia commercial area; specifically, the mean depth, global integration, and number of road connections were revealed (Table III).

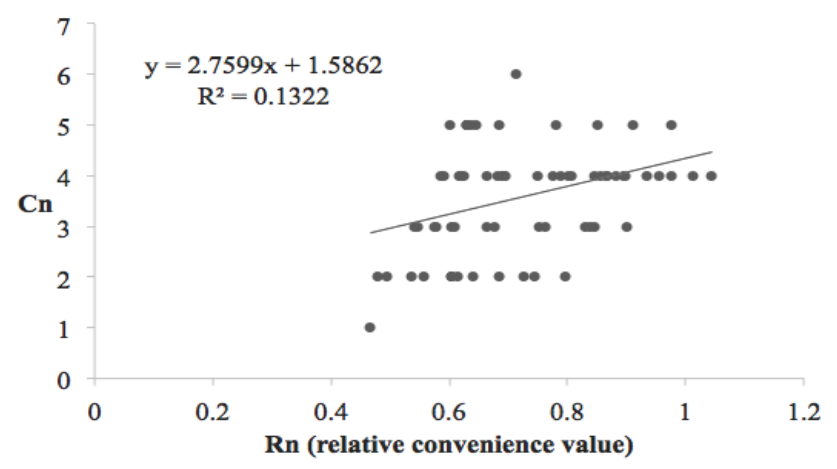

Fig 8. Distribution of RNs and Numbers of Connections.
The mean depth was 6.152 , mean global integration was 0.723 , and mean number of connections was 3.582. According to Fig. 8, RN and $\mathrm{CN}$ show synergy with a weak positive correlation $\left(\mathrm{R}^{2}=0.1322\right)$; a large $\mathrm{R}^{2}$ (maximum $=1$ ) implies that which user are more able to understand the spatial distribution within an area. Furthermore, high global integration would indicate a high number of connections; however, the positive correlation between them was weak and minor differences between the number of connections and RN was observed. The number of connections did not directly influence RN. Instead, it was because the Fengjia commercial area includes only short sections of roads and has a small area, thereby leading to a predominantly high RN.

The global integration values of roads are visualized in Fig. 9, where a red line represents a high RN and a blue line represents a low RN. In addition, Fig. 9 depicts the distribution of road $\mathrm{RN}$ values in the commercial area; the highest $\mathrm{RN}$ was observed at the middle section of Fuxing Road, with the RN decreasing toward the two ends. Overall, the RN decreased gradually upward from McDonald's, and roads with relatively high $\mathrm{RN}$ were located in the commercial district.

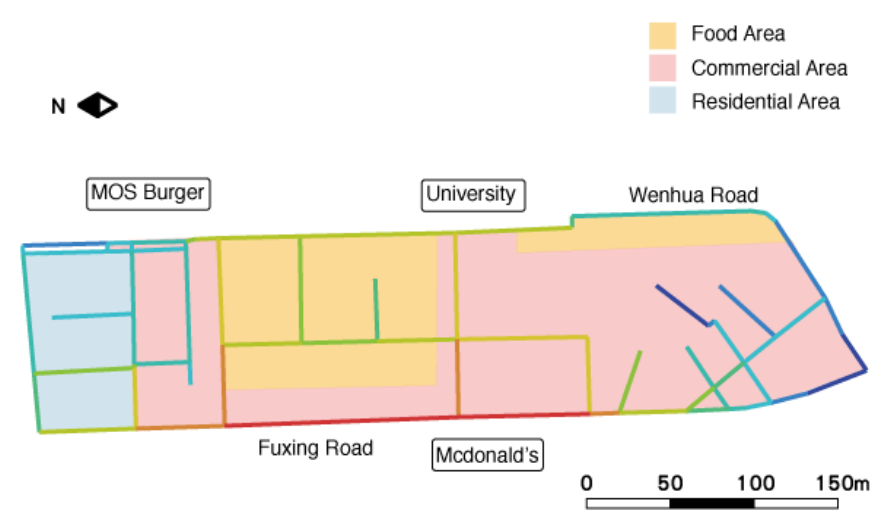

Fig 9. RN of Roads in the Fengiia Commercial Area.

\section{B. Persona Design}

1) User segmentation per attribute: This study recorded the stop points and observed purchasing behaviors of 65 people from 40 groups in the Fengjia commercial area during the night market's opening hours (6-8 PM). According to the onsite observation results, this study divided the research subjects into three segments and compiled these people's stop points as well as the routes they took. Subsequently, to analyze the distributions of RNs and customers from different segments in-depth, we divided the research subjects and defined each segment's purchase characteristics (Table IV). 
TABLE IV. USER SEGMENTS

\begin{tabular}{|l|l|l|l|}
\hline Segment & $\begin{array}{l}\text { Numbers of } \\
\text { groups and } \\
\text { people }\end{array}$ & Spatial behaviors & $\begin{array}{l}\text { Purchase } \\
\text { characteristics }\end{array}$ \\
\hline Locals & $\begin{array}{l}\text { Six groups } \\
\text { (Seven } \\
\text { people) }\end{array}$ & $\begin{array}{l}\text { Are familiar with the } \\
\text { district distributions } \\
\text { and routes and entering } \\
\text { the commercial area } \\
\text { from various entrances }\end{array}$ & $\begin{array}{l}\text { Know what and } \\
\text { how to purchase }\end{array}$ \\
\hline Backpackers & $\begin{array}{l}30 \text { groups } \\
\text { (46 people) }\end{array}$ & $\begin{array}{l}\text { Have researched the } \\
\text { area, they know where } \\
\text { to locate services they } \\
\text { require, and enter the } \\
\text { commercial area from } \\
\text { various entrances }\end{array}$ & $\begin{array}{l}\text { Have rough } \\
\text { purchasing plans } \\
\text { and are open to } \\
\text { changes }\end{array}$ \\
\hline $\begin{array}{l}\text { Tour group } \\
\text { travelers }\end{array}$ & $\begin{array}{l}\text { Four groups } \\
\text { (12 people) }\end{array}$ & $\begin{array}{l}\text { Are unfamiliar with the } \\
\text { area's spatial structure } \\
\text { and enter the } \\
\text { commercial area from } \\
\text { the entrance near } \\
\text { McDonald's on Fengjia } \\
\text { Road }\end{array}$ & $\begin{array}{l}\text { Are uncertain of } \\
\text { what to buy, and } \\
\text { thus explores the } \\
\text { commercial area }\end{array}$ \\
\hline
\end{tabular}

- Segment 1: Locals consisting of six groups (one group comprised two people, with seven people in total);

- Segment 2: Backpackers consisting of 30 groups (46 people); and

- Segment 3: Tour group travelers consisting of four groups (12 people).

Table IV shows that the people most familiar with the area's spatial structure were locals (Segment 1), whereas the people least familiar with the spatial structure were tour group travelers (Segment 3). Regarding purchase characteristics, Segment 1 exhibited the most certain attitudes, whereas Segment 3 exhibited the most uncertain attitudes. Segment 2's spatial behaviors and purchase characteristics, namely familiarity with the area and certainty of purchases, were all between those of Segments 1 and 3. Accordingly, the characteristics of the three segments were distinct and their spatial behaviors revealed their distributions in the area.

2) Persona and Spatial Behaviors: The spatial behaviors (routes taken and stop points) of people from the three segments were inputted into the QGIS software package to identify hot spots. According to Fig. 10, locals (Segment 1) started their journey predominantly from entrances at the university's main entranceway or McDonald's and mainly proceeded north toward the yellow district (food district) or south toward the night market section on Wenhua Road.

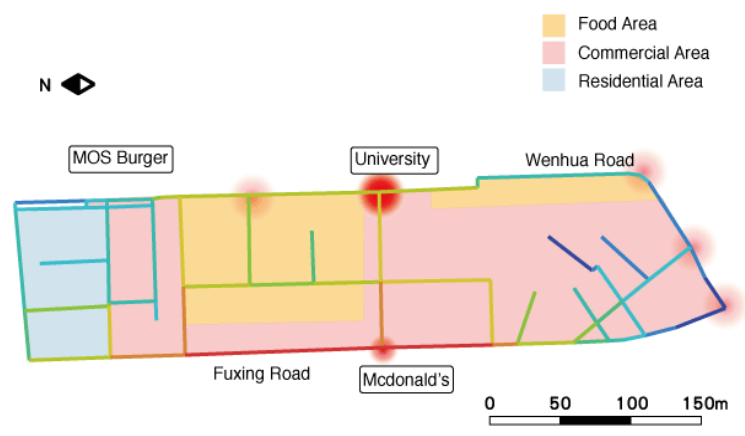

Fig 10. Space Syntax Analysis Map: Stop Points of Segment 1.

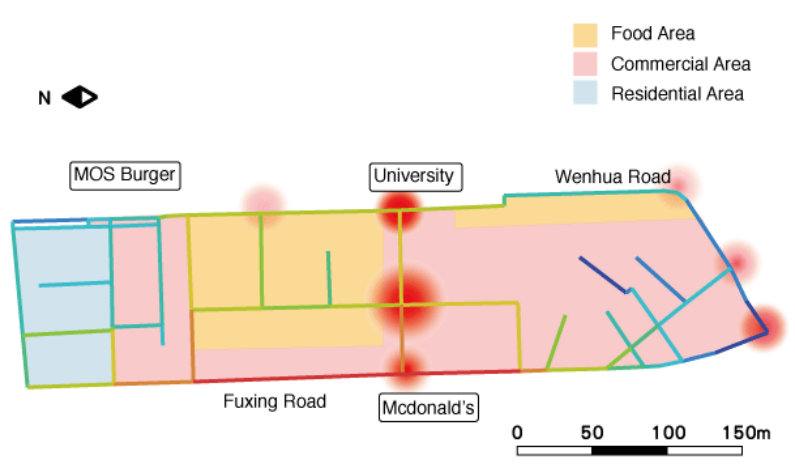

Fig 11. Space Syntax Analysis Map: Stop Points of Segment 2.

Backpackers (Segment 2; Fig. 11) started their journey mainly from road section with high RN (Fengjia Road) and moved south toward the yellow district, namely the night market section on Wenhua Road. The intersections of Fuxing Road and Wenhua Road became hot spots because they were adjacent to transport and parking spots.

Tour group travelers (Segment 3 ) predominantly stopped at places with high RN (Fig. 12); however, their stop points were scattered all throughout this area. They mainly spread along the roads from two landmarks, namely the night market entrance at the university's main entranceway and that near the McDonald's.

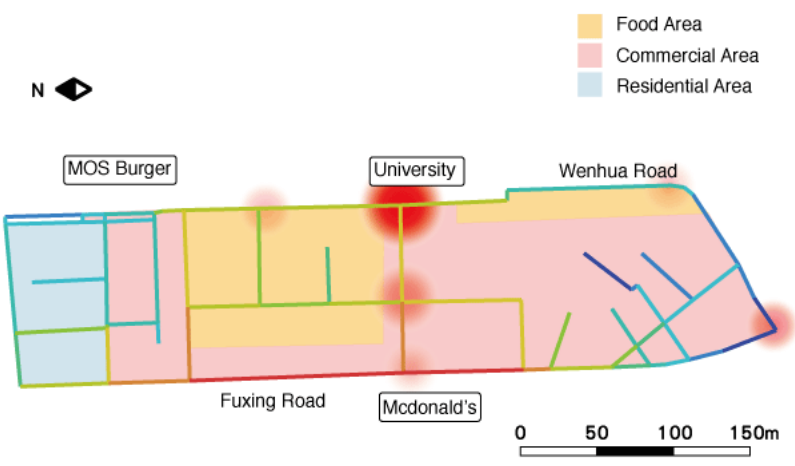

Fig 12. Space Syntax Analysis Map: Stop Points of Segment 3. 


\section{Crowd Behavior Analysis}

Crowd behavior analysis involves using a computer to simulate pedestrian movement and crowd behavior in a space. It provides insights into pedestrian spatial behaviors, namely the relationship between space and pedestrian behavior and the interaction between space and pedestrians. According to the descriptions of user personas, pedestrians entered the Fengjia commercial area from various entrances; therefore, the crowd behavior we observed at different entrances was analyzed separately. Crowd density was presented using a color gradient from red (highest density) to blue (lowest density).

Fig. 13 presents the predicted crowd behavior without any focused entrance. The most crowded area (red section) is located at the center of Fengiia Road, with crowd density decreasing outward along the road.

Fig. 14 illustrates the predicted distribution of crowds using the entrance near McDonald's; the results were consistent with those shown in Fig. 14 (no focused entrance), which might be because the landmarks in this commercial were located at both ends of this road section. Accordingly, future research could use McDonald's as the main entrance to investigate crowd behavior and hot spots in this commercial area. In addition to McDonald's being a landmark, it was also a crucial indicator because it was located at the top of a key road in this area.

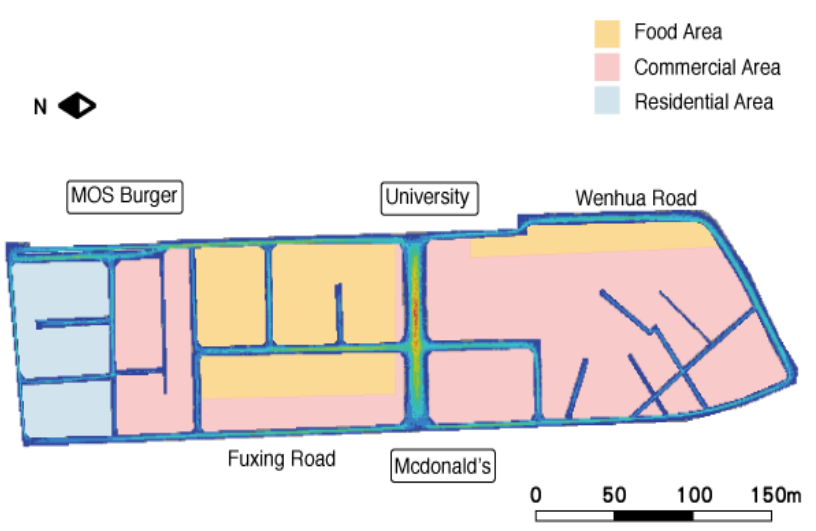

Fig 13. Predicted Crowd Behavior in the Fengjia Commercial Area without any Focused Entrance.

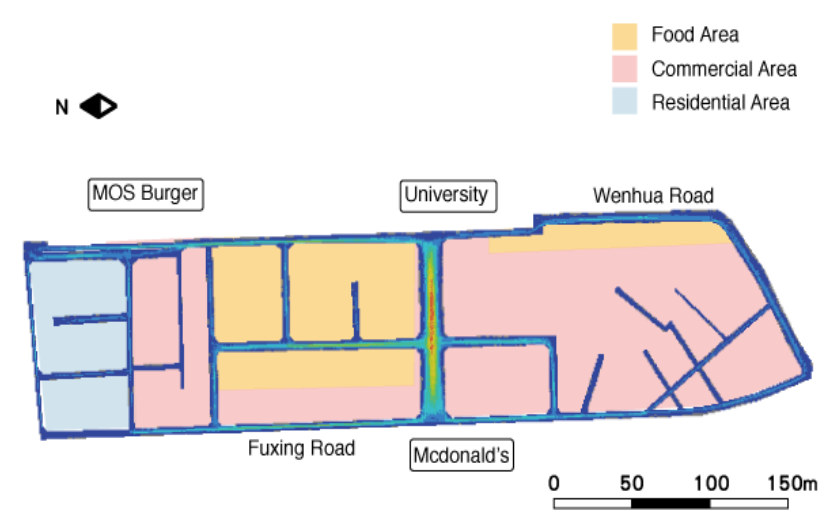

Fig 14. Predicted Crowd Behavior in the Fengjia Commercial Area: Using McDonald's as the Entrance.
Signage for Fengjia night market were provided at the intersection of Fuxing Road and Wenhua Road as well as near the parking lot located at the southern end of the commercial area. Fig. 15 illustrates the predicted crowd behavior of people entering the commercial area at the intersection of Fuxing Road and Wenhua Road; the most crowded area is on the section of Wenhua Road between the intersections with Fengjia Road and Fuxing Road. According to the night market's layout, this road section was one of two food districts in the commercial area. Food street vendors were located on both sides of this road section, which was adjacent to the commercial district; therefore, this road section exhibited the densest crowds. When we compared a panoramic photograph of the intersection of Fuxing Road and Wenhua Road with the map in Fig. 15, the right end of the panoramic photo indicated the entrance shown in Fig. 15. Because a signage for Fengjia night market was provided at this intersection, people driving there along Fuxing Road usually entered the commercial area from this entrance.

Fengjia University is a crucial landmark in this commercial area as well as a commonly used entrance into the commercial area for students. Fig. 16 presents the predicted crowd distribution in the commercial area of people entering from the university's main entranceway. Fengiia Road has the densest crowds, which is similar to the result when people enter through the entrance near McDonald's. This means that people entering the commercial area from the two ends of Fengjia Road mostly gathered along this section of road.

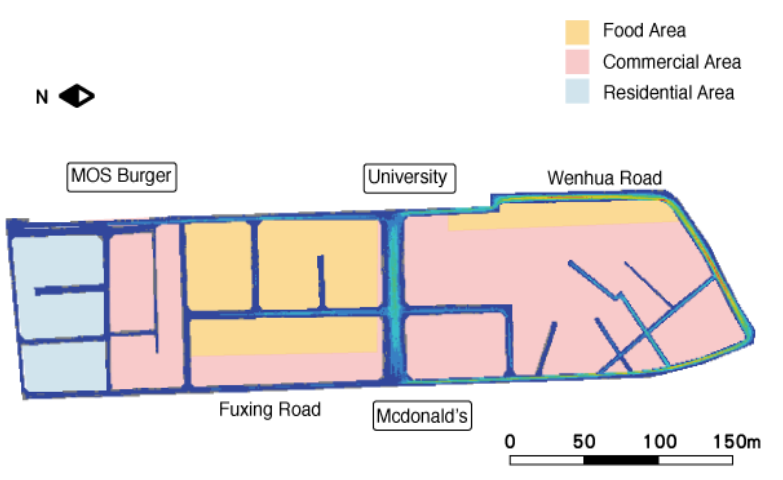

Fig 15. Predicted Crowd Behavior in the Fengjia Commercial Area: Intersection of Fuxing and Wenhua Roads as the Entrance.

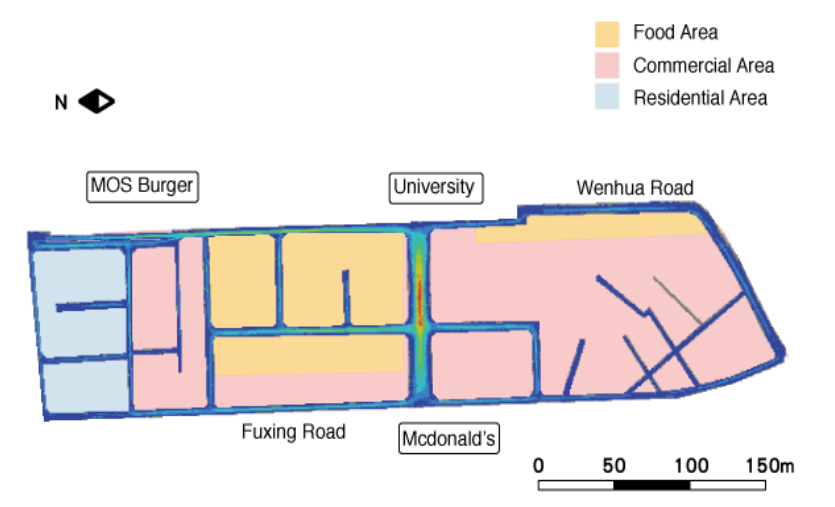

Fig 16. Predicted crowd behavior in the Fengiia Commercial Area: Fengjia University's Main Entranceway as the Entrance. 


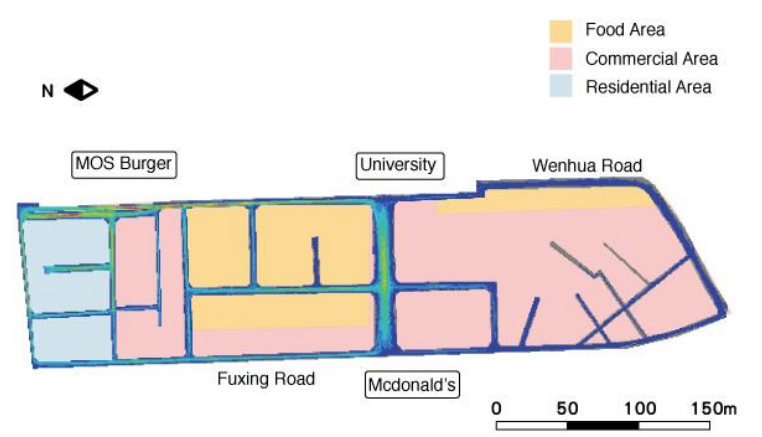

Fig 17. Predicted Crowd Behavior in the Fengjia Commercial Area: University Entranceway Near MOS Burger as the Entrance.

Another entranceway to Fengjia University is near MOS Burger located at the northern end of the commercial area (indicated by the red arrow in Fig. 17). Therefore, we also predicted the distribution of people entering the commercial area from the university entranceway near MOS Burger. According to Fig. 17, the most crowded area is on the Wenhua Road section near MOS Burger, and this road section passes through both food and residential districts. A reason might be that students at the university usually entered the commercial area through the university entranceway near MOS Burger. These maps of predicted crowd behavior can be used to plan and design services for students of the university.

\section{User Movement Simulation and Visualization Analysis}

1) Collection cartographic data of the research site: To record the road locations of pedestrians in the Fengjia commercial area, this study employed cartographic data provided by the Taiwan MAP Service (https://maps.nlsc.gov.tw/) to pinpoint the locations of buildings, outline edges, and centerlines of the roads in the research site, as well as to define the site borders. Using digital cartographic data, Google Maps street view, and $360^{\circ}$ panoramic photos and videos captured onsite, we produced a map of the research site with the edges and centerlines of roads indicated (Fig. 18 and 19). The blue-outlined road sections are those within the research site and the red lines are the road centerlines. According to our onsite observations, both vehicles and pedestrians are allowed on Fuxing Road and Xi'an Street; thus, the edges of the research site along the two sections of road were defined as being 3-5 $\mathrm{m}$ from buildings outward toward the roads. The remaining road sections were all only for pedestrian entry at night, and thus their road edges were defined as those shown in the cartographic data.

2) Setting conditions for persona movement: Following relevant studies related to GANs, which have predominantly adopted graphic data in their training processes, the present study collected graphic data of user movement, adapted its source code from another study [25], and employed a KerasGAN. A sufficient amount of actual data is required before training a GAN; therefore, randomly simulated user movement data were produced before sufficient data were collected. According to the persona definitions in Table IV, we defined their spatial behaviors according to the characteristics of the three segments (Table V), which served as the conditions and constraints used for subsequent simulations.

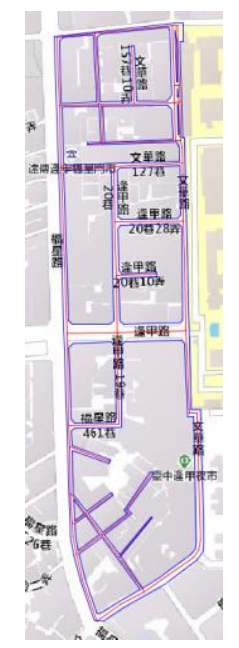

Fig 18. Road Edges and Centerlines in the Research Site.
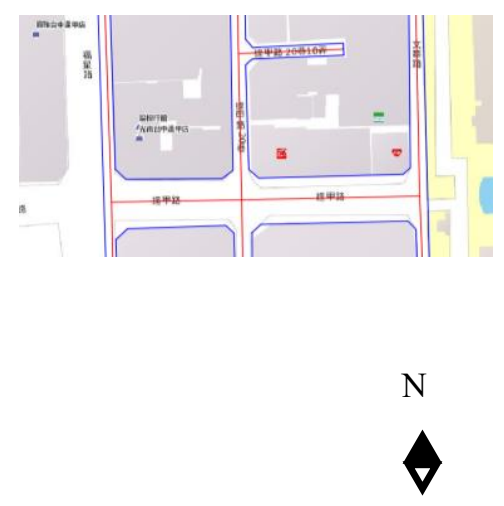

Fig 19. Zoomed View of the Road Map.

Table V. Spatial Behavior Settings of Personas

\begin{tabular}{|l|l|l|l|}
\hline Segments & $\begin{array}{l}\text { Max. walking } \\
\text { distance per } \\
\text { minute }\end{array}$ & $\begin{array}{l}\text { Max. } \\
\text { stopping } \\
\text { time }\end{array}$ & Spatial behaviors \\
\hline $50 \mathrm{~m}$ & $\begin{array}{l}30 \\
\text { minutes }\end{array}$ & $\begin{array}{l}\text { They know what to purchase, } \\
\text { and thus tend to head to their } \\
\text { destinations for purchases } \\
\text { immediately after entering the } \\
\text { commercial area and stop at } \\
\text { shopping spots for relatively } \\
\text { short durations. }\end{array}$ \\
\hline Backpackers & $40 \mathrm{~m}$ & $\begin{array}{l}\text { Thy usually have planned } \\
\text { their routes in advance } \\
\text { according to shopping } \\
\text { categories they are interested } \\
\text { in. They orient themselves in } \\
\text { this area after entry and make } \\
\text { necessary changes to their plan. } \\
\text { They stop at shopping spots for } \\
\text { varying durations. }\end{array}$ \\
\hline $\begin{array}{l}\text { Tour group } \\
\text { travelers }\end{array}$ & $20 \mathrm{~m}$ & $\begin{array}{l}\text { They are relatively open to } \\
\text { what to purchase; bound to a } \\
\text { tour group, they stop at limited } \\
\text { places in the commercial area } \\
\text { and for limited durations. }\end{array}$ \\
\hline
\end{tabular}


According to the purchase characteristics of the three customer segments and our onsite observations, the customers' spatial behaviors were defined as being distinct from one another. To generate pedestrian movement, we defined the maximum walking distance per minute and stopping durations in the commercial area of the three customer segments according to their spatial behaviors.

The interval between each two consecutive simulated positions of a pedestrian was determined at 1 minute in our simulation experiment. Therefore, in the commercial area, we recorded pedestrian positions, defined their maximum walking distance per minute, and tracked their movement sequences and directions to generate their movement tracks, which consisted of the recorded points. The largest point of each track indicated the position where the pedestrian spent the longest time during the recorded journey. For example, a recorded duration of 30 minutes yielded 31 points (including the starting point) on a pedestrian's movement track.

3) User movement visualization and analysis: According to the characteristics (Table IV) and spatial behaviors (Table V) of the customer segments, this study proceeded with data collection in the commercial area and finalized the sample size at 45 groups of people, with a total of 89 people; the sample comprised 32 groups of locals ( 55 people), 10 groups of backpackers (22 people), and three groups of tour group travelers (12 people). The main entrances of the commercial area comprised those at the three landmarks and one at the intersection of Wenhua Road and Fuxing Road. These graphic data were inputted into the Keras-GAN to simulate graphic user movement data; the process was as follows. The collected movement data were inputted in the Keras-GAN for training, and each training cycle involved 30 pictures. Fig. 20 presents the results at the $1000^{\text {th }}$ training cycle, during which a large amount of noise was observed. Fig. 21 shows the results at the $1600^{\text {th }}$ training cycle, during which the road edges became clearer and the simulated movement tracks were mostly located within the research site.

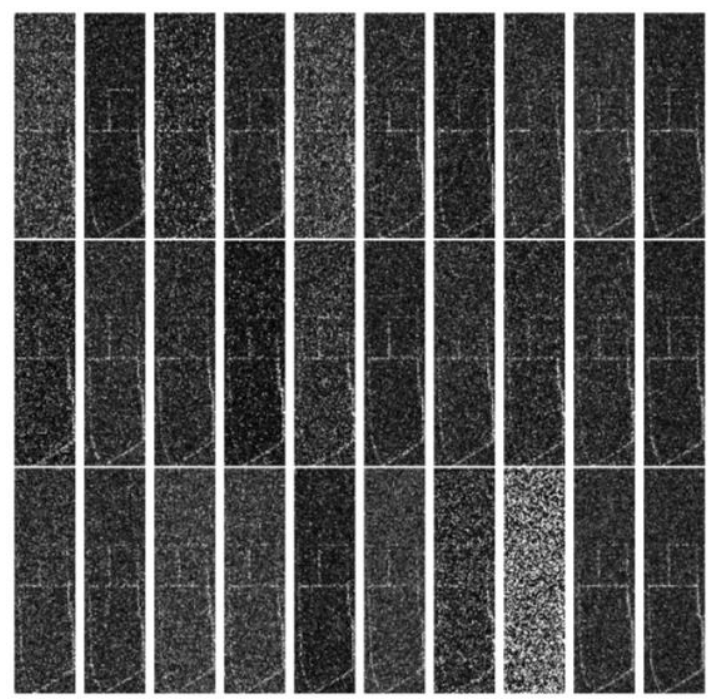

Fig 20. Simulated Results of Movement Tracks at the $1000^{\text {th }}$ Training.

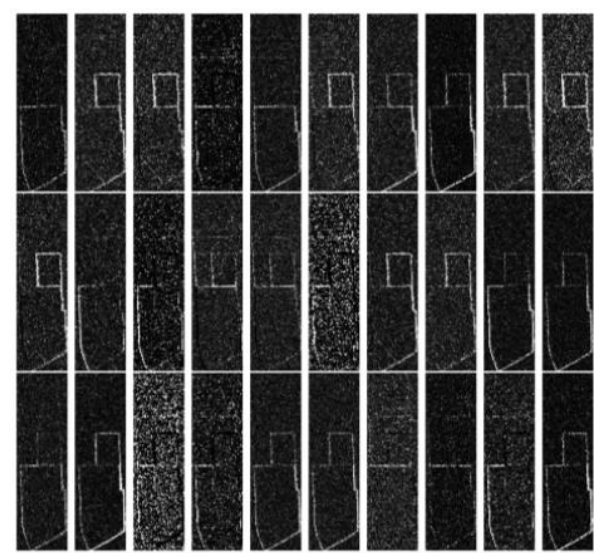

Fig 21. Simulated Results of Movement Tracks at the $1600^{\text {th }}$ Training Cycle.

We continued the training and outputted a graphic result for each 100 training cycles. Fig. 22 presents the movement track results of the $2000^{\text {th }}$ training cycle; the variation among the graphic results became smaller. Fig. 23 is the result of the $2400^{\text {th }}$ training cycle, after which the movement track results started to converge. If the overfitting problem is encountered during ANN training, the ANN might produce pictures that are highly similar to the original inputs. Therefore, this study set the GAN's maximum training cycle to 2400 .

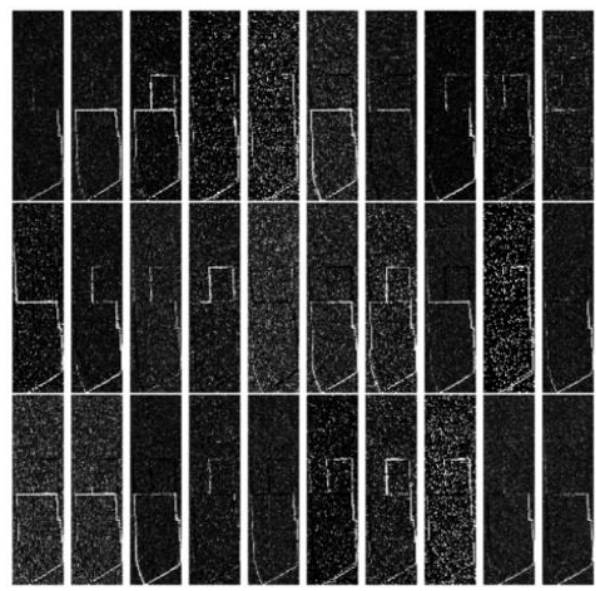

Fig 22. Simulated results of movement tracks at the $2000^{\text {th }}$ training cycle.

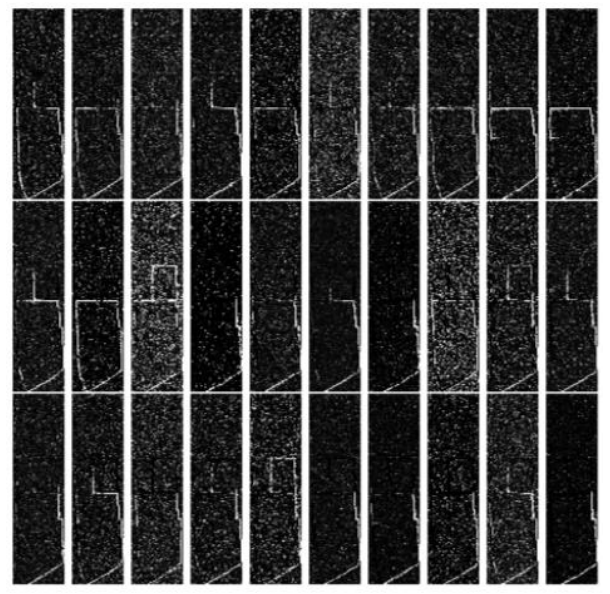

Fig 23. Simulated results of movement tracks at the $2400^{\text {th }}$ training cycle. 


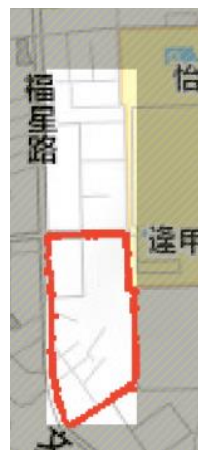

(1)

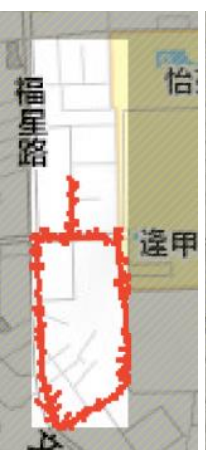

(2)

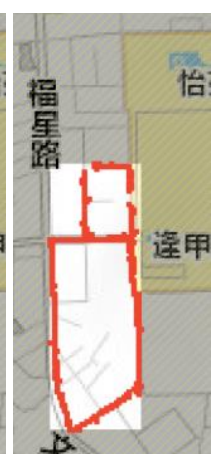

(3)
Fig 24. Pictures of the Three Most Common Movement Tracks Simulated During Training.

We extracted one simulated result every 100 training cycles between the $1600^{\text {th }}$ and $2400^{\text {th }}$ training cycles; the nine simulated results provided a total of 270 pictures of movement tracks, and the three pictures with the most occurrences were combined with the cartographic data for subsequent analyses. Fig. 24(1) shows that most pedestrian movement was concentrated at the south of the commercial area, namely from Fengjia Road southwards to the night market section on Wenhua Road and back to Fengjia Road through Fuxing Road. Fig. 24(2) presents a pedestrian movement track on Lane 20 of Fengjia Road (food district), in addition to that shown in (1). Fig. 24(3) includes both pedestrian movement tracks shown in (1) and (2) and shows an additional pedestrian movement track starting from Lane 20 of Fengjia Road through to Lane 127 of Wenhua Road and finally back to Fengjia Road.

The Keras-GAN-simulated movement results indicated that the pedestrian movement was predominantly concentrated at the south of the commercial area, despite it having four entrances at the McDonald's on Fengjia Road, the main entranceway of Fengjia University, the university entranceway near MOS Burger, and the intersection of Wenhua Road and Fuxing Road. Our onsite observations showed that the southern half of Wenhua Road constituted the main part of the night market, and therefore, most pedestrian movement tracks were observed in this part of the commercial area. Moreover, various food vendors operating along the northern part of Lane 20 of Fengjia Road to Lane 127 of Wenhua Road attracted people to walk around this area.

\section{RESEARCH CONCLUSIONS AND RECOMMENDATIONS}

This study used the global integration of space syntax to analyze hot spots where pedestrians most frequently stopped; the Keras-GAN to simulate three movement track graphic results; and the deformed wheel theory to investigate the relationship between the commercial area and pedestrians. The following conclusions were derived from the results:

1) Global integration and movement track simulation results: Global integration refers to the connectivity and integration of a road in a global space. Fig. 9 shows that road intersection with the highest global integration value is McDonald's. Similarly, the simulated movement results (Fig. 24) revealed that only one of the three road sections starting from McDonald's (northward along Fuxing Road) is not among the most commonly occurring movement tracks, whereas the other two road sections from McDonald's are (toward Fengjia University to the east and southward along Fuxing Road). These results indicated that McDonald's as a landmark showed the highest connectivity with other roads within the commercial area; pedestrians had to pass the McDonald's when they entered and exited the area.

2) Hot spot analysis of pedestrian segments and training results of the movement track simulation: When we compared Fig. 10-12, which show the hot spots of different pedestrian segments, with Fig. 24, we observed the pedestrian hot spots to all be located on the most commonly occurring movement tracks in the simulation results. Therefore, the results of the movement track simulation and those of the pedestrian hot spots were positively correlated; future researchers who wish to analyze the movement tracks of different pedestrian segments more in-depth may also include predictions of pedestrian hot spot distributions in their research.

3) Deformed wheel and movement track simulation results: As previously described, deformed wheel theory is used to discuss the synergetic relationships between two spaces. According to Fig. 13-17, the Fengjia Road section is in the center of the commercial area, connecting roads on the commercial area borders, and thus integrates places near the borders. This result is consistent with that in Fig. 24, according to which Fengjia Road is where pedestrian movement is mostly concentrated. In addition, our onsite observations verified that Fengjia Road was the central road of the commercial area; specifically, this road divided the commercial area in the middle and connected the two food districts with the commercial district. Wenhua Road and Fuxing Road served as the commercial area borders, and their intersections with Fengjia Road were two main entrances of the commercial area. The section of Fengjia Road was short but served as a crucial hub of the commercial area, and thus should be seen as the primary focus of the area's service design. According to our onsite observations and the length and integration values of roads located in the northern part of the commercial area, namely the area to the north of Fengjia Road, only the food district had relatively dense crowds, whereas the other places in this area did not exhibit high spatial characteristics as a commercial area.

Overall, the global integration values and pedestrian hot spots in the Fengjia commercial area were highly mutually dependent; therefore, the global values of places in this commercial area may be incorporated into the spatial design for its service provision. The deep-learning simulation of pedestrian movement tracks and spatial characteristics revealed by space syntax could be used as a reference for each other. From the perspective of place creation in the deformed wheel theory, district layout greatly affected the affordances of roads in terms of service design. The southern part of the Fengjia commercial area was officially planned to be the main food district, and thus, frequent place interaction was observed along roads here. Regarding place identity and user behaviors in the night market, place creation on the road that constitutes the 
commercial area's southern border facilitated the fulfillment of user needs in this part of the commercial area; this approach to user-need fulfillment is widely applied in urban planning. Moreover, place realization was observed on Fengjia Road; specifically, it is connected to Fengjia University's main entranceway and plays an essential role in the place identity of both the commercial area and the university.

Following are our recommendations for future studies discussing the relationship between and elements of personabased movement track simulation and space syntax:

- Studies may consider examining whether tour group and backpackers stay overnight in the Fengjia commercial area. Those staying in hotels located in this commercial area will spend more time moving around the area, and thus will stop at more places than will those who do not stay overnight. A longer duration of user movement data collection will facilitate more comprehensive possibilities of simulated graphic results.

- This study inputted 45 groups of people (89 people) for GAN simulation, which included relatively limited data from tour group travelers (three groups; 12 people). Thus, future research may expand the sample size of tour group travelers. Moreover, future research may perform Keras-GAN simulations for the three personas separately to examine their movement simulation results individually.

- In this study, we did space syntax analysis and pedestrian movements simulation by GAN in a specific commercial area. There is currently no relevant overall application and interdisciplinary research. In the future, the relevant evaluation methods can be used to understand the practicality of each function in the cross-domain research from the professional perspective in order to extend service design for this research.

\section{ACKNOWLEDGMENT}

The authors acknowledge the technical support on GAN simulation application by Mr. Kai-Wan Cheng.

\section{REFERENCES}

[1] Soufiane, F., Said, M., \& Atef, A., "Sustainable urban design of historical city centers", Energy Procedia, vol. 74, pp. 301-307, 2015.

[2] Hillier, B., \& Hanson, J., The Social Logic of Space. Cambridge. Cambridge University Press, 1984.

[3] Ratti, C., "Urban texture and space syntax: some inconsistencies", Environment and Planning B: Planning and Design, vol. 31, pp. 487499, 2004.

[4] Volchenkov, D., \& Blanchard, P., "Scaling and Universality in City Space Syntax: between Zipf and Matthew", Physica A, vol. 387, pp. 2353-2364, 2008.

[5] Zhao, J., \& Künzli, O., "An introduction to connectivity concept and an example of physical connectivity evaluation for underground space",
Tunnelling and Underground Space Technology, vol. 55, pp. 205-213, 2016.

[6] Yesiltepe, D. \& Kubat, A., "Impact of Bridges on Spatial Transformation of Urban Pattern: The case of Golden Horn, Istanbul", En 24th ISUF International Conference. Book of Papers. Editorial Universitat Politècnica de València. pp. 935-942. doi:10.4995/ISUF2017.2017.6059, 2018

[7] Hillier, B., Space is the Machine, A Configurational Theory of Architecture. Cambridge University Press, 1986.

[8] Daneshpour, S. A., Abbaszadegan, M., \& Elahi, M., "The Morphology of Qom; The Study on Spatial Configuration Changes of The City (1956-2021)", Space Ontology International Journal, vol. 6, pp. 27-36, 2017

[9] Önder, D. E., \& Gigi, Y., "Reading urban spaces by the space-syntax method: A proposal for the South Haliç Region", Cities, vol. 27, pp. 260-271, 2010.

[10] Choi, A.-S., Young-Ook Kim, Oh, E.-S., \& Kim, Y.-S, “Application of the space syntax theory to quantitative street lighting design". Building and Environment, vol. 41, pp. 355-366, 2006.

[11] Amorim, L. M. d. E., Filho, M. N. M. B., \& Cruz, D, "Urban texture and space configuration: An essay on integrating socio-spatial analytical techniques." Cities, vol. 39, pp. 58-67, 2014.

[12] Hanson, J., "Decoding Houses and Homes", Cambridge: Cambridge University Press, 1988.

[13] Koohsari, M. J., Kaczynski, A. T., Giles-Corti, B., \& Karakiewicz, J. A., "Effects of access to public open spaces on walking: Is proximity enough?", Landscape and Urban Planning, vol. 107, pp. 92-99, 2013.

[14] Manzo, L. C., \& Devine-Wright, P., Place Attachment: Advances in Theory, Methods and Applications. New York: Routledge, 2014.

[15] Carpio-Pinedo, J., "Urban bus demand forecast at stop level: Space Syntax and other built environment factors", Evidence from Madrid. Procedia - Social and Behavioral Sciences, vol. 160, pp. 205-214, 2014.

[16] Li, Y., Xiao, L., Ye, Y., Xu, W., \& Law, A., "Understanding tourist space at a historic site through space syntax analysis: The case of Gulangyu, China", Tourism Management, vol. 52, pp. 30-43, 2016.Alfonzo, M. A., "To Walk or Not to Walk? The Hierarchy of Walking Needs." Environment and Behavior, vol. 37, pp. 29, 2005.

[17] Turner, A., "From axial to road-centre lines: a new representation for space syntax and a new model of route choice for transport network analysis" Environment and Planning B: Planning and Design, vol. 34, pp. 539-555, 2007.

[18] Turner, A., Penn, A., \& Hillier, B., "An algorithmic definition of the axial map", Environment and Planning B: Planning and Design, vol. 32, pp. 425-444, 2005.

[19] Klarqvist, B., "A Space Syntax Glossary", NORDISK ARKITEKTURFORSKNING, vol. 2, 1993.

[20] Jiang, B., Claramunt, C., \& Klarqvist, B., "Integration of space syntax into GIS for modelling urban spaces", Journal of Applied Gerontology, vol. 2, 2000.

[21] Enrico di, B., Luca, P., \& Matteo, C., "A Multivariate Analysis of The Space Syntax Output For The Definition Of Strata In Street Security Surveys", DEP - series of economic working papers, 2011.

[22] Lerman, Y., Rofè, Y., \& Omer, I., "Using Space Syntax to Model Pedestrian Movement in Urban Transportation Planning”, Geographical Analysis, vol. 46, 2014.

[23] Arjovsky, M., Chintala, S., \& Bottou, L, "Wasserstein GAN", Retrieved from arXiv:1701.07875, Retrieved Sep. 2018.

[24] Lynch, K., The Image of the City. The Technology Press \& Harvard University Press, 1960.

[25] Mohammadi, M., Al-Fuqaha, A., \& Oh, J.-S., "Path Planning in Support of Smart Mobility Applications using Generative Adversarial Networks", Retrieved from arXiv:1804.083966v1, Retrieved Mar. 2019. 